\title{
DESAIN DAN IMPLEMENTASI WEBSITE E-COMMERCE BERBASIS CONTENT MANAGEMENT SYSTEM (CMS) PADA MITRA ADHETAMA RAYA
}

\author{
Samsinar $^{1 *}$, Muhammad Rizky Nugraha ${ }^{2}$ \\ ${ }^{12}$ Fakultas Teknologi Informasi, Sistem Informasi, Universitas Budi Luhur

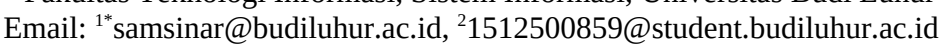 \\ (* : coressponding author)
}

\begin{abstract}
Abstrak-Mitra Adhetama Raya adalah sebuah badan usaha milik perorangan yang bergerak di dalam bidang penjualan alat kesehatan (alkes). Permasalahan yang ada saat ini, Mitra Adhetama Raya belum memiliki adanya media website yang digunakan sebagai alat promosi dan penjualan produk alat kesehatan, dengan adanya permasalahan tersebut maka penulis menganalisis kebutuhan sistem dan model bisnis dari Mitra Adhetama Raya dengan memanfaatkan Bussiness Model Canvas $(B M C)$ dan Unified Model Language (UML). Dalam membangun web sebagai media penjualan maupun promosi (ecommerce) menggunakan Content Management System (CMS) Wordpress dan plugin-plugin pendukung agar terbentuk sebuah media penjualan online yang diharapkan menjadi solusi dari permasalahan yang ada sehingga dapat meningkatkan hasil penjualan dan membantu aktivitas pengolahan data menjadi lebih akurat dan efektif, proses penjualan tidak hanya dapat dilakukan di sekitar area rumah sakit terdekat saja tetapi dapat mencakup area yang lebih luas lagi dan juga mampu memberikan informasi lebih detail dan lebih banyak menawarkan promosi kepada pelanggan.
\end{abstract}

Kata Kunci: Bussiness Model Canvas, Alat Kesehatan, UML, WordPress, penjualan online

\begin{abstract}
Mitra Adhetama Raya is an individual-owned business entity engaged in the sale of medical devices (medical devices). The problem that exists today, Mitra Adhetama Raya does not have a website media that is used as a tool to promote and sell medical devices products, with the problem, the author analyzes the needs of the system and business model of Mitra Adhetama Raya by utilizing Bussiness Model Canvas (BMC) and Unified Model Language (UML). In building the web as a sales and promotion media (e-commerce) using Wordpress Content Management System (CMS) and supporting plugins to form an online sales media that is expected to be the solution to existing problems so as to increase sales results and help activities so that data processing becomes more accurate and effective, the sales process can not only be done around the nearest hospital area but can cover a wider area and also be able to provide more detailed information and more offers promotion to customers.
\end{abstract}

Keywords: Bussiness Model Canvas, Medical Devices, UML, WordPress, online commerce

\section{PENDAHULUAN}

Teknologi informasi sudah memasuki hampir kesemua bidang usaha, sistem informasi ini sangat dibutuhkan untuk melakukan pengolahan data yang akurat. Dengan adanya teknologi informasi dapat membuat suatu sistem terkomputerisasi dimana sistem ini sangat mendukung kemudahan, kecepatan dalam mengumpulkan, mengolah dan menyimpan data lebih efektif. Perkembangan internet saat ini semakin maju untuk salah satu pendorong berkembangnya e-commerce. Internet merupakan salah satu jaringan global yang menghubungkan jaringan computer diseluruh dunia, sehingga komunikasi dan interaksi antar pihak penjual dan pembeli menjadi lebih mudah.

Melihat adanya potensi akan risiko yang akan dihadapi oleh perusahaan bisnis, maka penerapan teknologi e-commerce merupakan salah satu aspek yang penting yang dapat dikembangkan dalam rangka menunjang keberhasilan siklus hidup produk dari proses produksi hingga sampai bagaimana produk tersebut dipasarkan [1]. Sebagai contoh untuk mempercepat dan meningkatkan penjualan maka perlu melihat perkembangan teknologi informasi yang sangat pesat seperti survei yang dilakukan oleh Asosiasi Pengguna Jasa Internet Indonesia tahun 2017 [2]. Beberapa hal inilah yang menjadikan e-commerce Indonesia mempunyai potensi untuk menarik minat investor seperti Alibaba untuk menanamkan modal investasi pada dua e-commerce yang paling banyak dicari di Indonesia yaitu Lazada dan Tokopedia.

Mitra Adhetama Raya adalah sebuah badan usaha milik perorangan yang bergerak di dalam bidang penjualan alat kesehatan (alkes). Permasalahan yang ada saat ini, Mitra Adhetama Raya belum memiliki adanya media website yang digunakan sebagai alat promosi dan penjualan produk alat kesehatan yang sebelumnya hanya tertuju untuk kalangan rumah sakit saja. Mitra Adhetama Raya dalam memasarkan produk alkes hanya melalui toko fisik dan hanya dengan media sosial Instagram yang digunakan oleh pelanggan untuk melihat foto produk alat kesehatan yang dijual serta menggunakan aplikasi whatsapp untuk proses pemesanan. Dengan adanya peran e-commerce yang dapat membantu proses penjualan dan promosi, maka penulis mengembangkan 
aplikasi website berbasis E-Commerce menggunakan CMS wordpress yang bertujuan dapat memberikan solusi dalam menyelesaikan permasalahan yang ada.

Penelitian terdahulu dengan judul penelitian "Implementasi E-Commerce Menggunakan Content Management System Untuk Pemasaran Produk Pada Lumi Distro Dengan Pendekatan Business Model Canvas”. Pada penelitian ini bertujuan untuk memberikan Solusi alternative pada Lumi Distro dengan membuatkan website e-commerce agar penjualan semakin meningkat, yang menggunakan metode object oriented, Implementasi web menggunakan CMS Wordpress dan menggunakan BMC sebagai analisis model bisnis agar strategi penjualan dapat tesusun dengan baik dan maksimal dan meluas [3].

Penelitian terdahulu selanjutnya dengan judul penelitian "Sistem Informasi Penjualan Online E-Commerce Menggunakan CMS Wordpress Pada Toko Soraya Shop Dengan Menerapkan Metode RAD” Penjualan Soraya Shop ini masih menjadi masalah untuk mendapatkan tujuan perusahaan, dikarenakan penjualan dan sistem transaksi masih secara manual. Dengan adanya masalah tersebut, Soraya Shop menemukan solusi untuk menyelesaikan masalah yang ada dengan membuat Wordpress dan RAD. Tujuan Soraya Shop menggunakan Wordpress untuk meningkatkan loyalitas pelanggan agar bertahan, penjualan yang semakin meningkat, pemasaran yang semakin meluas dan menjaga hubungan pelanggan agar terciptanya kesetiaan pelanggan terhadap Soraya Shop [4].

Penelitian terdahulu selanjutnya yang berjudul "Implementasi E-Commerce Sebagai Media Penjualan Online” Dengan perkembangan teknologi yang maju, pada saat ini memicu pada pelaku bisnis untuk berlombalomba menjadi yang terbaik, penawaran website e-commerce tidak hanya yang berbayar. Terdapat juga penawaran website yang tidak berbayar juga tersedia secara gratis di Internet. Salah satu website e-commerce gratis tersebut adalah Opencart [5].

Penelitian terdahulu selanjutnya dengan judul "Perancangan Sistem Informasi Penjualan Berbasis ECommerce Studi Kasus Toko Kun Jakarta”. Toko Kun adalah suatu usaha yang bergerak dibidang penjualan pakaian muslimah. Masalah yang di hadapi oleh Toko Kun adalah sistem penjualan yang masih dilakukan secara offline, jangkauan toko, penyimpanan data dan pencetakan laporan masih menggunakan pencatatan kedalam arsip. Metode yang digunakan dalam penelitian adalah model waterfall. Hasil dan tujuan penelitian ini adalah menghasilkan sistem informasi penjualan berbasis e-commerce yang nantinya dapat membantu dalam pengolahan data, promosi dan transaksi yang dilakukan melalui media website e-commerce [6].

Berdasarkan penelitian terdahulu dan latar belakang yang sudah dijelaskan diatas, maka penulis melakukan penelitian dalam mendesain dan mengimplementasikan website e-commerce berbasis CMS Wordpress sesuai dengan kebutuhan dari Mitra Adhetama Raya, perbedaan penelitian yang dilakukan dengan penelitian terdahulu terdapat pada penggunaan Business Model Canvas untuk menganalisis model bisnis yang baru agar menghasilkan model bisnis yang lebih maksimal kemudian Didalam web commerce yang dibuat terdapat adanya Teknik Search Engine Optimization (SEO) untuk membantu meningkatkan traffic web. Hasil dari penelitian ini adalah desain dan Implementasi website berbasis E-Commerce menggunakan CMS wordpress yang dapat meningkatkan hasil penjualan produk dan membantu aktivitas pengelolaan data menjadi lebih akurat dan efektif, proses penjualan tidak hanya dapat dilakukan di sekitar area rumah sakit terdekat saja tetapi dapat mencakup area yang lebih luas lagi dan juga mampu memberikan informasi lebih detail dan lebih banyak menawarkan promosi kepada pelanggan.

\section{METODE PENELITIAN}

\subsection{Metode Pengumpulan Data}

Dalam menyelesaikan penelitian ini, penulis membutuhkan data yang dihubungkan dengan topik yang dibahas. Adapun metode yang digunakan dalam pengumpulan data adalah sebagai berikut:

a. Wawancara

Penulis mengumpulkan data-data yang dibutuhkan dengan cara wawancara secara langsung kepada para informan guna mendapatkan informasi mengenai masalah dan kebutuhan yang diinginkan oleh pengguna.

b. Pengamatan

Penulis mengumpulkan data dengan cara mengamati langsung ke tempat riset. Penulis dapat mengetahui dengan jelas bagaimana cara kerja dari perusahaan Mitra Adhetama Raya.

c. Analisis Dokumen

Mengumpulkan data berdasarkan dokumen-dokumen yang berhubungan dengan objek penelitian, yang nantinya akan di analisis lebih lanjut.

d. Studi Literatur

Penelitian ini melakukan Studi Literatur review dari berbagai buku serta referensi lain yang sesuai dengan permasalahan yang diamati. Studi ini dilakukan baik melalui buku yang ada pada perpustakaan maupun $e$ - 
INDONESIA JOURNAL INFORMATION SYSTEM (IDEALIS)

Volume 4, Nomor 1, Januari 2021

ISSN 2684-7280 (online)

Halaman 73-82

available online at http://jom.fti.budiluhur.ac.id/index.php/IDEALIS/index

book serta dari penelitian sejenis terdahuku berupa jurnal, yang nantinya akan dijadikan sebagai bahan acuan kegiatan penelitian.

\subsection{Tahapan Penelitian}

Tahapan penelitian yang dilakukan oleh penulis mencakup tahapan awal hingga akhir pelaksanaan penelitian dan merupakan bagian penting dalam sebuah penelitian yang akan berpengaruh pada hasil penelitian. Berikut adalah langkah-langkah atau tahapan penelitian. Lihat Gambar 1:

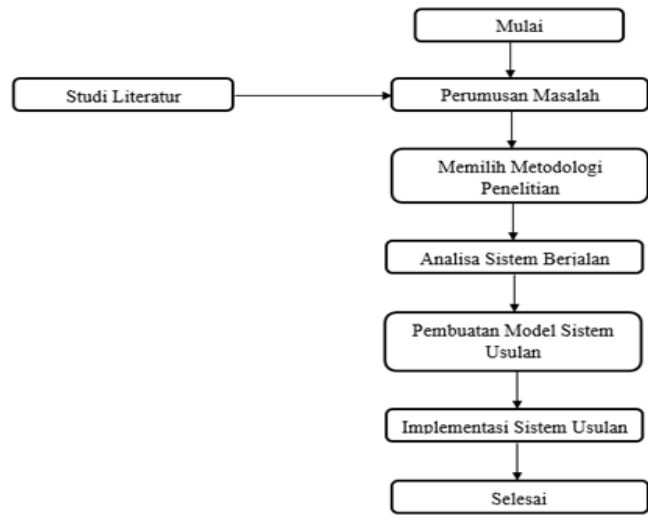

Gambar 1. Tahapan Penelitian

Pada Gambar 1, menjelaskan bahwa tahapan-tahapan dari penelitian yang dilakukan, berikut adalah penjelasan tahapan secara detail sebagai berikut:

a. Perumusan Masalah

Pada tahapan rumusan masalah yang terjadi pada objek penelitian sekaligus merumuskan tujuan dari penelitian dan merupakan hasil dari kegiatan observasi dan wawancara langsung kepada beberapa stake holder staf dan admin pada Mitra Adhetama Raya.

b. Studi Literatur

Pada tahap studi literatur ini dilakukan untuk mendapatkan teori tentang layanan penjualan alat kesehatan pada Mitra Adhetama Raya, serta teori umum yang terkait dengan rumusan permasalahan. Metode yang dilakukan penelitian dengan membaca berbagai referensi dari artikel ilmiah baik berupa jurnal, prosiding dan lainnya yang telah dipublikasikan.

c. Menentukan Metodelogi

Pada tahap ini, penulis menentukan metodologi yang digunakan dalam menyelesaikan permasalahan dalam penelitian. Adapun metodologi yang digunakan dalam penelitian ini adalah Research Applied (penelitian terapan)

d. Analisis Sistem

Pada tahap ini, peneliti melakukan analisis proses bisnis sistem menggunakan Activity Diagram.

e. Pembuatan Model Data Sistem.

Pada tahap ini, peneliti melakukan sebuah identifikasi kebutuhan sistem, memodelkan sistem dengan menggunakan Use Case Diagram

f. Implementasi Sistem

Tahapan akhir ini impementasi sistem menggunakan Content Management System (WordPress)

\subsection{Metode Analisis}

Business Model Canvas(BMC) adalah metode analisis yang dipakai dalam melakukan penelitian ini. Metode BMC digunakan untuk mendapatkan model bisnis yang baru agar menghasilkan model bisnis yang lebih maksimal [7]. Diharapkan dengan adanya metode ini dapat membantu bagaimana cara memetakan model ini dapat membantu bagaimana cara memetakan model bisnis pada suatu organisasi yang sedang dianalisis menjadi pengembangan strategi penjualan model bisnis yang lebih baik lagi bagi Mitra Adhetama Raya yang juga memanfaatkan Search Engine Optimization (SEO) guna meningkatkan ranking web pada mesin pencarian bertujuan untuk pemasaran agar mudah dicari oleh calon pelanggan. 
INDONESIA JOURNAL INFORMATION SYSTEM (IDEALIS)

Volume 4, Nomor 1, Januari 2021

ISSN 2684-7280 (online)

Halaman 73-82

available online at http://jom.fti.budiluhur.ac.id/index.php/IDEALIS/index

\section{HASIL DAN PEMBAHASAN}

\subsection{Model Bisnis}

Pada penelitian ini model yang digunakan yaitu Business Model Canvas. Model ini yang merupakan alat untuk memodifikasi model bisnis baru pada perusahaan untuk membuat strategi yang lebih tepat. Didalam BMC terdapat 9 elemen [8]. Elemen-elemen ini membantu memudahkan perusahaan untuk menemukan aktivitas baru yang dapat dilakukan untuk pengembangan stategi bisnisnya. Lihat Gambar 2:

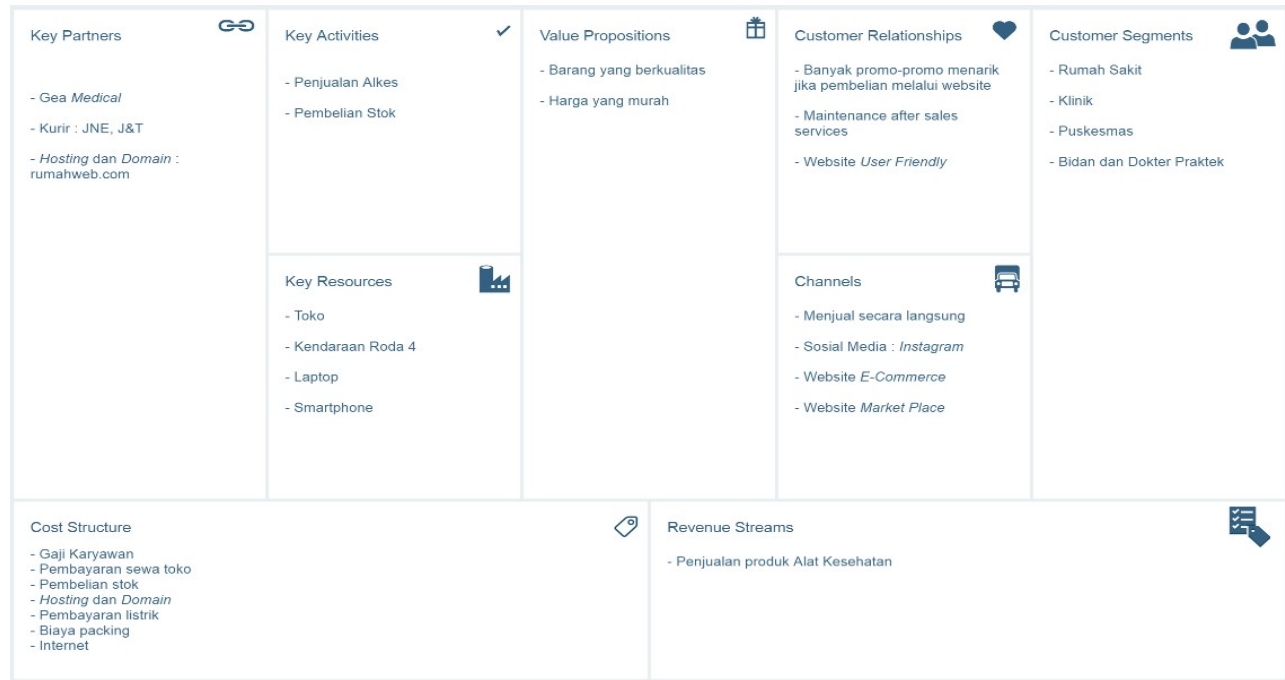

Gambar 2. Business Model Canvas

Pada Gambar 2, menjelaskan 9 blok elemen Business Model Canvas yang dianalisis pada Mitra Adhetama Raya diantaranya:

a. Customer Segments

Blok elemen ini merupakan bagian penting dalam melakukan aktifitas bisnis saat ini dan kedepannya, segmen ini untuk menentukan sasaran segmentasi pelanggan dari penjualan produk alat kesehatan pada perusahaan Mitra Adhetama Raya, tanpa penetapan atau penentuan tujuan pelanggan maka bisnis tidak dapat berjalan dengan baik nantinya. Dalam hal ini yang difokuskan untuk customer segment adalah pihak rumah sakit, klinik, puskesmas, bidan dan dokter praktek yang menjadi sasaran penjualan pada Mitra Adhetama Raya.

b. Value Propositions

Blok elemen ini berisi tentang nilai tambah yang akan membuat bisnis dari perusahaan Mitra Adhetama Raya terlihat menarik dan berbeda dengan bisnis lainnya yang sejenis. Yang membuat produk alat kesehatan ini berbeda dengan yang lain adalah alat kesehatan dengan kualitas terbaik dan harga yang ditawarkan dan kecepatan respon dari manager perusahaan jika customer ingin memesan.

c. Channels

Blok elemen ini sama pentingnya dengan blok elemen lain yang merupakan media yang digunakan untuk memasarkan produk agar bisa sampai ke tangan customer. Channel merupakan bagaimana perusahaan dapat memberikan segala informasi, distribusi dan penjualan kepada customer. Media atau cara Mitra Adhetama Raya mengjangkau pihak rumah sakit. Pemesanan bisa dengan cara manual secara langsung, menggunakan sosial media, dan e-commerce menggunakan website.

d. Customer Relationships

Pada BMC customer relationship merupakan jenis hubungan yang ingin dibangun pihak Mitra Adhetama Raya bersamaan dengan customer segment. Blok elemen ini merupakan cara berinteraksi untuk menjaga loyalitas konsumen, agar lebih banyak menjangkau pihak rumah sakit yang belum tahu produk alat kesehatan. Cara yang dilakukan Mitra Adhetama Raya untuk terus membuat promo-promo menarik jika pembelian melalui website, maintenance after sales service dan User Friendly.

e. Revenue Streams

Blok elemen ini merupakan struktur arus finansial dari perusahaan, produk atau jasa apa saja yang dapat memberikan pemasukan atau keuntungan dari value promosition yang ditawarkan. Arus finansial atau 
pendapatan merupakan inti dari model bisnis. Cara mendapatkan keuntungan. Keuntungan Mitra Adhetama Raya didapat dari hasil penjualan alat kesehatan di toko.

f. Key Activities

Blok elemen ini adalah bagian yang menjelaskan bagaimana aktivitas kunci atau strategi kompetitif yang dilakukan bisnis untuk menciptakan value proposition-nya. Aktivitas yang berhubungan dengan produktivitas bisnis yang berkaitan dengan sebuah produk dengan menjual produk alat kesehatan dan melakukan pemasaran.

g. Key Resources

Blok elemen ini merupakan sumber daya yang harus dimiliki perusahaan agar dapat kompetitif dalam menciptakan value perusahaan dari model bisnis dapat berfungsi. Sumber daya yang harus dimiliki atau dibutuhkan. Sumber daya yang penting bagi kelangsungan Mitra Adhetama Raya adalah bangunan toko, kendaraan roda 4, laptop atau komputer, internet, layanan server, listrik dan pegawai.

h. Key Partnerships

Blok elemen ini merupakan mitra atau partner yang mendukung organisasi agar selalu kompetitif. Pihakpihak yang bekerja sama dengan rangka memudahkan aktivitas bisnis. Key Partnership pada Mitra Adhetama Raya adalah distributor produk alat kesehatan Gea Medical, JNE dan J\&T sebagai jasa kurir.

i. Cost Structure

Blok elemen ini merupakan biaya-biaya apa saja yang di butuhkan yang harus di keluarkan untuk menjalankan keseluruhan aktivitas bisnis. Pengeluaran yang dibutuhkan untuk menjalani bisnis ini. Yaitu sewa bangunan toko, gaji karyawan, pembelian stok, sewa hosting dan domain, pembayaran listrik, biaya parkir dan internet.

\subsection{Hasil Implementasi E-Commerce}

\section{a. Activity Diagram}

Activity Diagram adalah menggambarkan workflow (aliran kerja) atau aktivitas dari sebuah sistem atau proses bisnis atau menu yang ada pada perangkat lunak [8]. Berikut adalah Activity Diagram alur bisnis pada Mitra Adhetama Raya sebagai berikut:

1. Proses Pemesanan Produk

Pada proses ini Customer mengunjungi website Mitra Adhetama Raya untuk melihat produk yang ada pada Mitra Adhetama Raya, jika customer tertarik customer dapat melakukan pemesanan melalui website dengan cara klik produk yang dipilih lalu, masukan jumlah produk yang mau dibeli selanjutnya, klik tombol add to cart atau langsung klik logo keranjang belanja jika kita mengarahkan cursor ke gambar produk. Lalu customer klik tombol View Cart untuk melihat produk yang sudah dipilih, customer juga bisa melihat produk yang sudah dipilih melalui klik logo keranjang belanja yang terdapat di pojok kanan atas halaman website. Jika customer telah selesai memilih produk, customer klik tombol Proceed to Checkout pada halaman View Cart. Bila customer sudah memiliki akun, customer dapat login dengan mengklik Click Here to Login, dan mengisi Billing Details untuk mengetahui biaya pengiriman. Jika belum memiliki akun customer melakukan register dengan menginput Nama, Country, Alamat, Kota, Provinsi, Kode Pos, No. Telp, Email, kemudian klik Create an Account dan mengisi Username dan Password. Setelah itu customer memilih metode pengiriman, lalu klik tombol Place Order untuk melihat detail order dan no rekening bank Mitra Adhetama Raya untuk melakukan pembayaran melalui transfer. Setelah customer melakukan order, customer menerima email invoice order, lalu admin menerima email bahwa telah terdapat order masuk dan admin mengubah status order menjadi On Hold pada halaman backend website. Jika customer tidak tertarik, customer dapat meninggalkan website. Lihat Gambar 3.

2. Proses Pembayaran dan Konfirmasi Pembayaran

Pada proses ini Customer melakukan pembayaran ke rekening bank yang terdapat pada halaman Place Order. Setelah melakukan transfer, customer melakukan konfirmasi pembayaran melalui website pada halaman konfirmasi pembayaran. Setelah itu admin menerima email konfirmasi pembayaran yang telah dilakukan oleh customer, lalu admin melakukan verifikasi konfirmasi pembayaran di halaman backend website, jika disetujui customer menerima email bahwa pembayaran telah di terima, jika tidak diterima customer menerima email pembayaran tidak diterima maka melakukan konfirmasi pembayaran ulang. Lihat Gambar 4.

3. Activity Diagram Proses Pengiriman Produk

Admin melakukan cek kondisi dan kelayakan produk yang akan dikirim sesuai pesanan, setelah itu admin melakukan packing produk lalu menyerahkan produk ke jasa pengiriman pihak ketiga yaitu JNE, lalu mendapatkan no resi pengiriman produk yang diperoleh, kemudian admin input no resi dan mengubah status order menjadi Shipped, lalu Customer menerima email order invoice dan no resi. Lihat Gambar 5. 
INDONESIA JOURNAL INFORMATION SYSTEM (IDEALIS)

Volume 4, Nomor 1, Januari 2021

ISSN 2684-7280 (online)

Halaman 73-82

available online at http://jom.fti.budiluhur.ac.id/index.php/IDEALIS/index

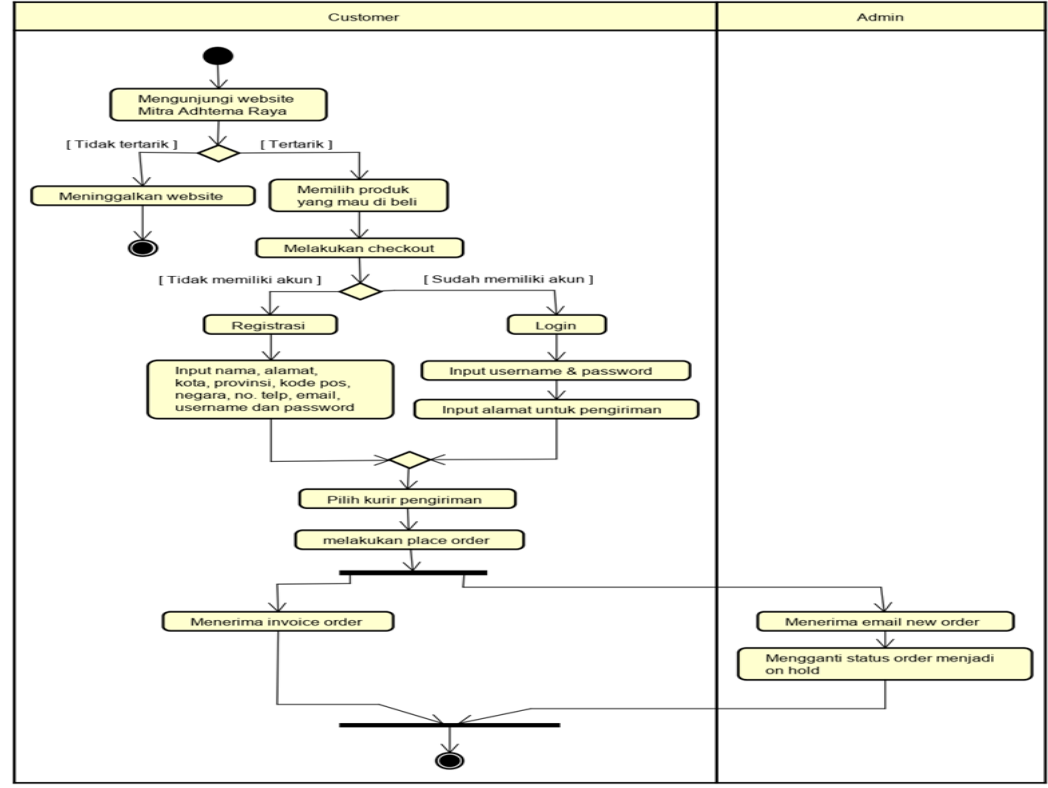

Gambar 3. Activity Diagram Proses Pemesanan Produk

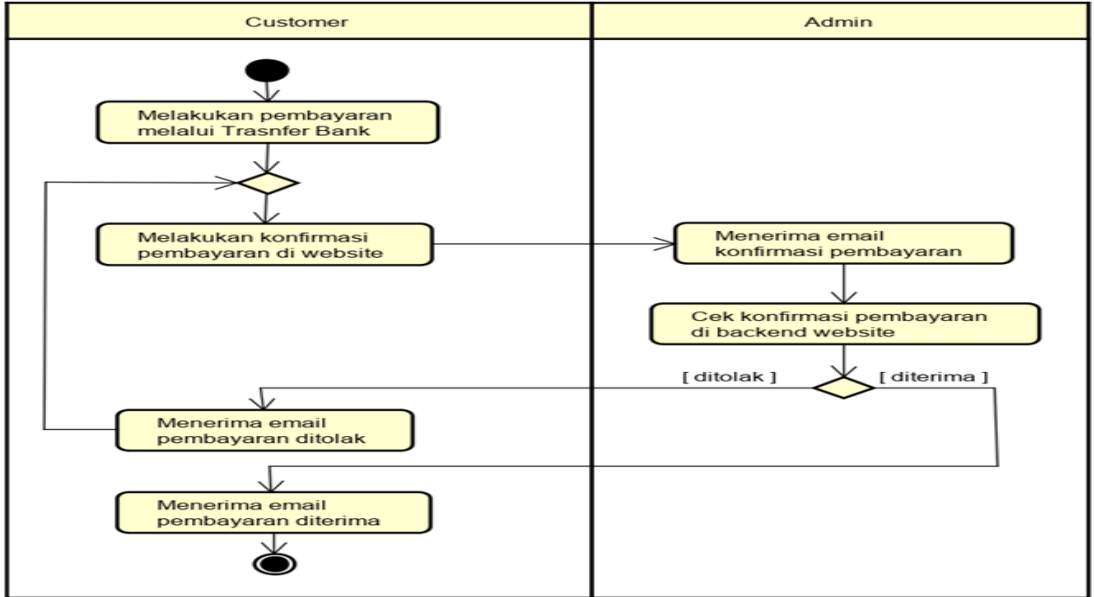

Gambar 4. Activity Diagram Proses Pembayaran dan Konfirmasi Pembayaran

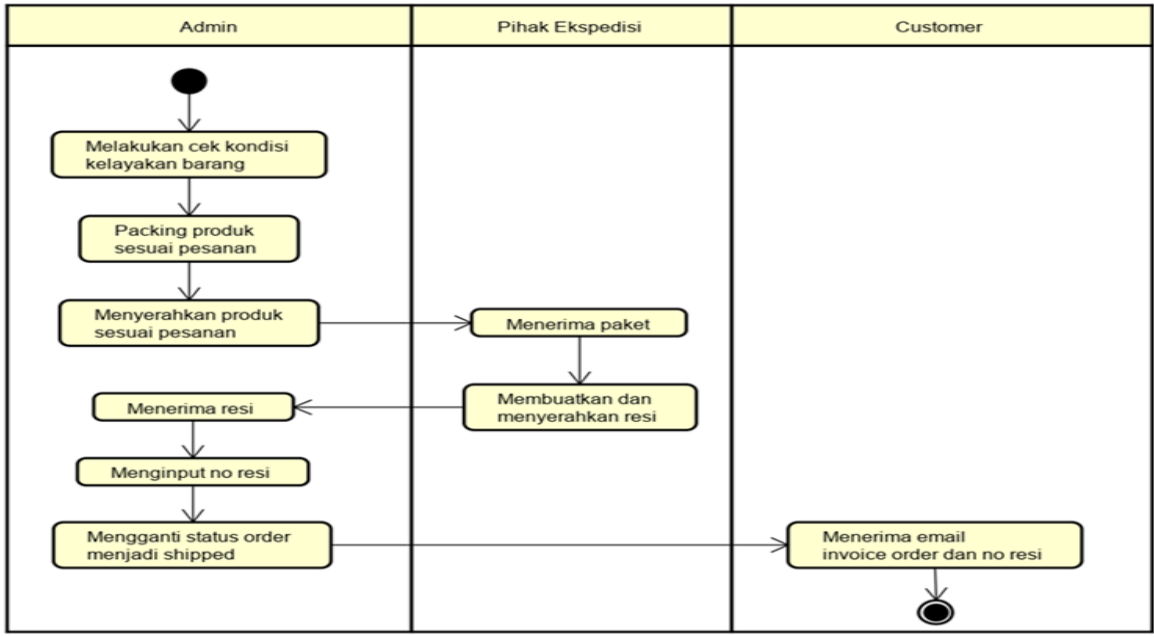

Gambar 5. Activity Diagram Proses Pengiriman Produk 


\section{b. Use Case Diagram}

Use Case Diagram adalah menggambarkan fungsionalitas yang diharapkan dari sebuah sistem [9]. Dibawah ini adalah beberapa gambaran-gambaran Use Case Diagram dalam penelitian ini adalah sebagai berikut:

1. Use Case Diagram Master

Pada Use Case Diagram master ini admin dapat mengentry produk, kategori dan tags. Sedangkan customer dapat melakukan pendaftaran dan login pada Gambar 6 berikut ini.

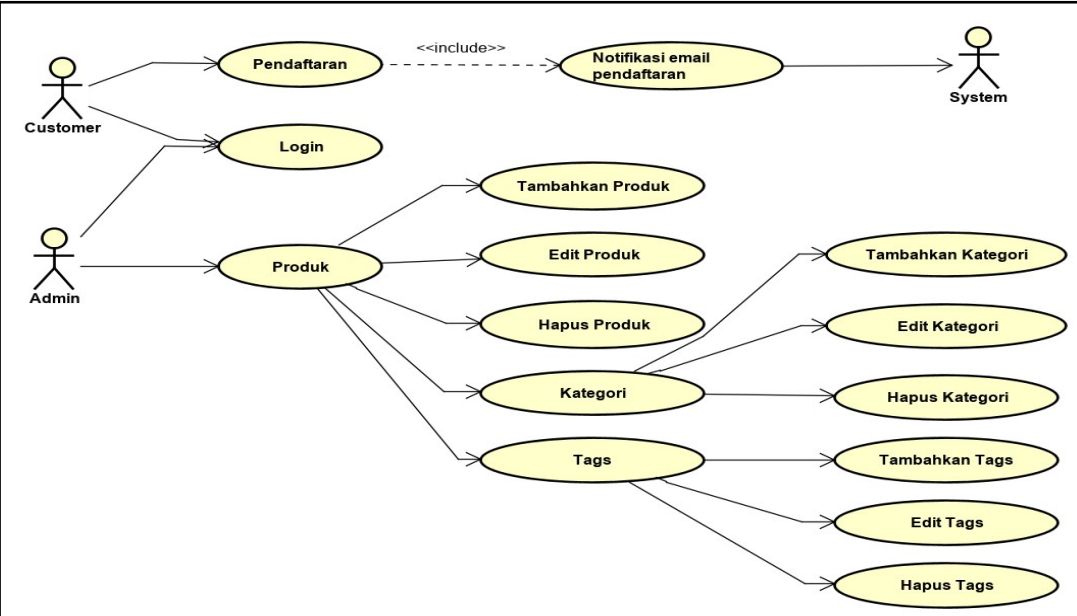

Gambar 6. Use Case Diagram Master

2. Use Case Diagram Transaksi

Pada Use Case Diagram transaksi ini Customer dapat mengentry order, masukan data pengiriman, confirm payment, lihat detail order dan mengecek resi. Sedangkan admin dapat melakukan verifikasi konfirmasi pembayaran, daftar order dan menginput no resi seperti yang terlihat pada Gambar 7 berikut ini.

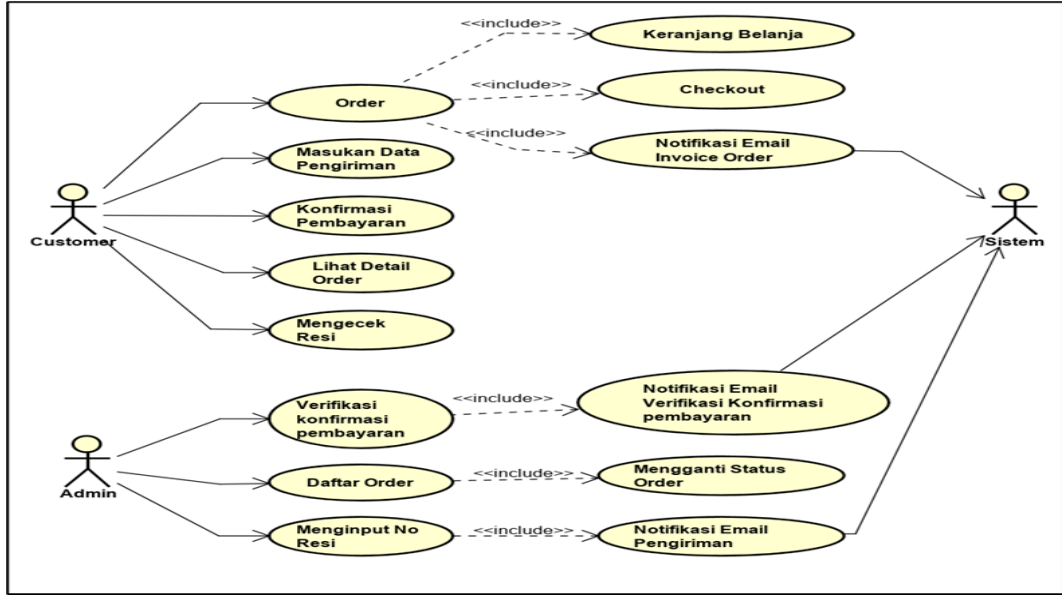

Gambar 7. Use Case Diagram Transaksi

\subsection{Interface E-Commerce}

a. Halaman Website Home

Halaman Home merupakan tampilan halaman awal website ketika pelanggan mengunjungi website mitraadhetamaraya.com. Pada halaman ini pelanggan dapat melakukan berbagai aktfitas misalnya masuk ke halaman my account, melihat produk-produk yang ditawarkan pada etalase dan pelanggan juga dapat melakukan pemesan langsung. Lihat Gambar 8. 


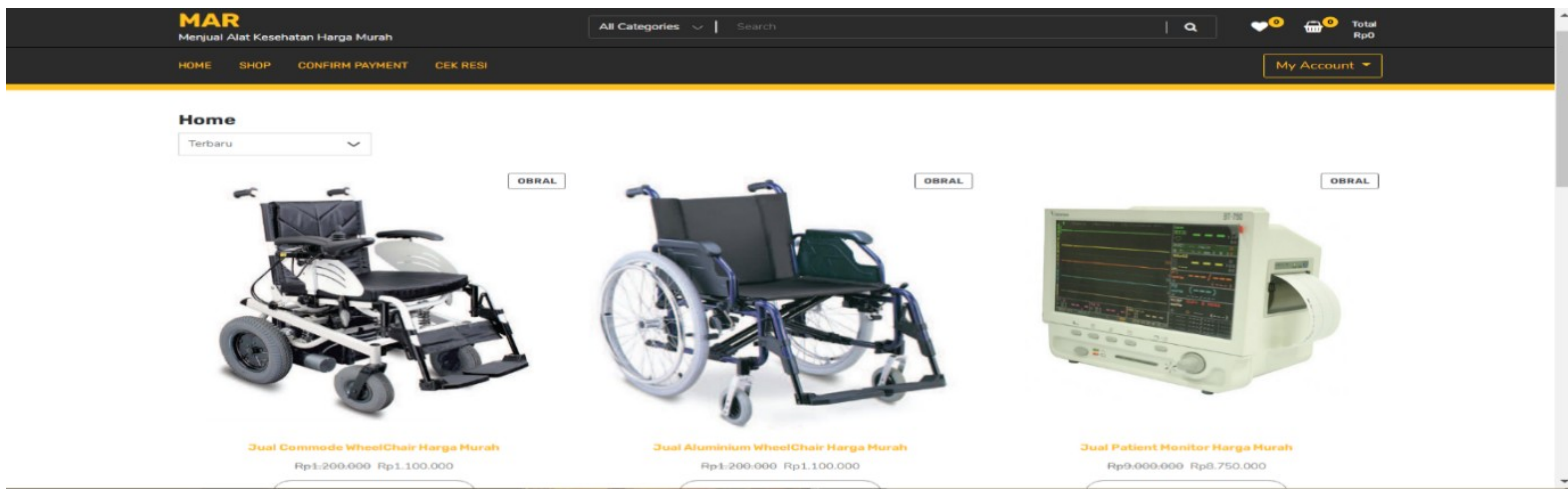

\section{Gambar 8. Halaman Home}

b. Tampilan Website Keranjang Belanja

Halaman Keranjang belanja atau cart ini merupakan halaman yang terdapat produk-produk yang ingin dipesan oleh pelanggan, jika produk yang terdapat dalam keranjang belanja ini yakin tidak ada perubahan lagi maka pelanggan dapat melanjutkan proses dengan lanjutkan ke Checkout untuk proses selanjutnya. Lihat Gambar 9:
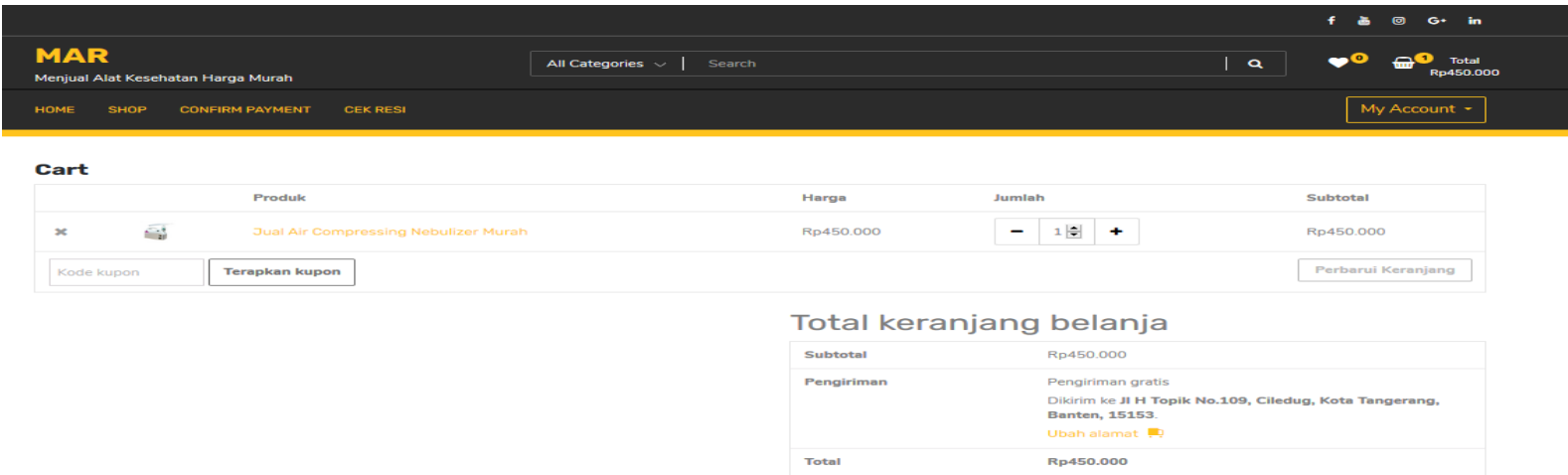

Lanjutkan ke Checkout

\section{Gambar 9. Halaman Keranjang Belanja}

c. Tampilan Website Checkout

Halaman Checkout ini merupakan tampilan halaman untuk mengisi data pelanggan secara detail sesuai dengan yang tertera pada halaman checkout yang wajib dilakukan selanjutnya pelanggan dapat melakukan pembayaran. Lihat Gambar 10:

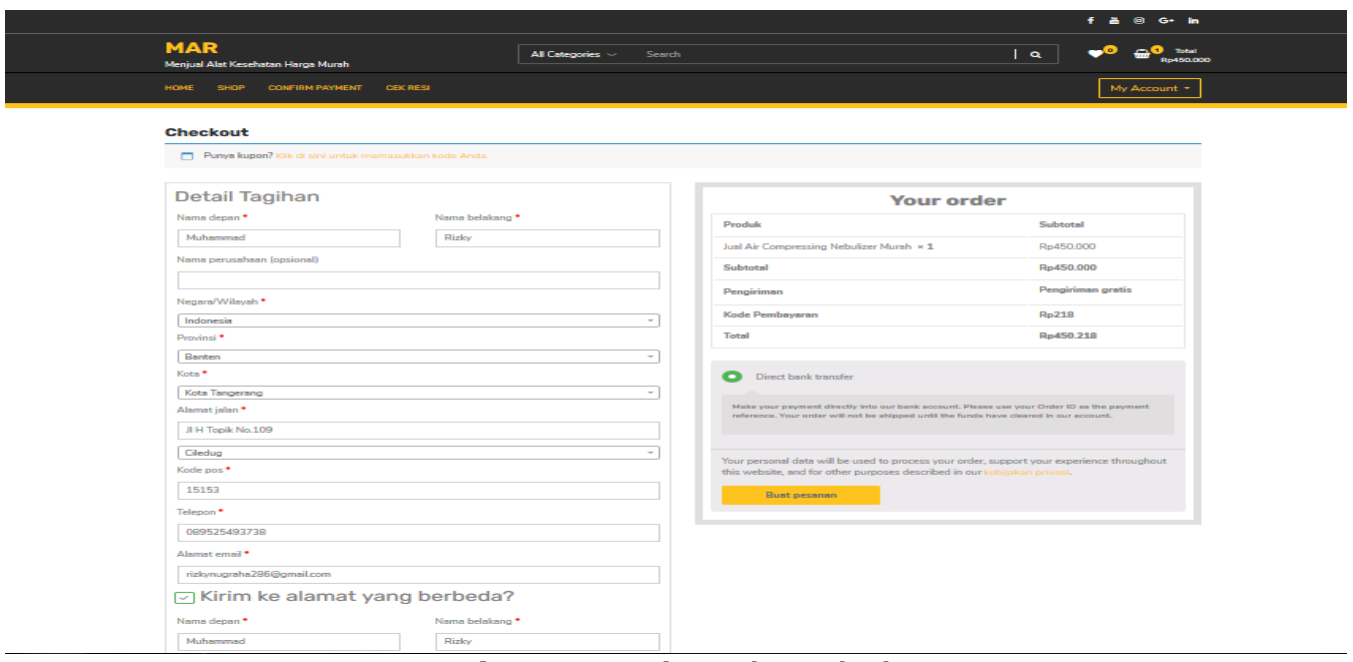

Gambar 10. Tampilan Website Checkout 
d. Tampilan Website Confirm Payment

Halaman Confirm Payment merupakan tampilan halaman pelanggan untuk melakukan konfirmasi pembayaran apabila sedang dalam Transaksi pembelian produk Alkes dan sudah melakukan pemesanan produk dimana pelanggan harus mengisi data yang tertera pada halaman ini yaitu mengisi data nama, order, bank transfer, transfer date, transfer slip atau bukti transfer, no.telpon, transfer amount sesuai dengan jumlah yang harus dibayarkan dan transfer date. Lihat Gambar 9:

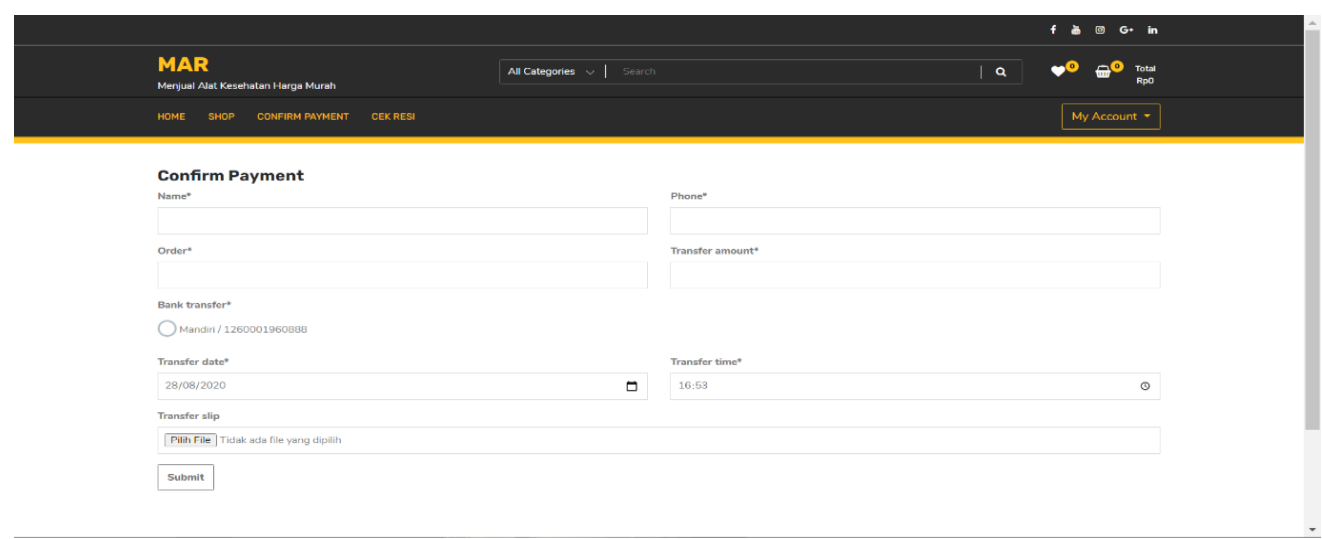

Gambar 11. Halaman Confirm Payment

\subsection{Search Engine Optimization (SEO)}

Strategi SEO dalam penerapan e-commerce pada Mitra Adhetama Raya, penulis menggunakan strategi SEO On Page. SEO On Page yang merupakan sebuah cara untuk mengoptimasi halaman dan konten website agar dapat di index oleh mesin pencari agar halaman website yang sudah dibuat berada diperingkat teratas atau dalam halaman Pertama (first page) [10]. Plugins yang digunakan Yoast SEO. Langkah yang dilakukan untuk Optimalisasi yaitu: Dalam melakukan optimalisasi pada setiap halaman produk website yaitu dengan penentuan keyphrase atau kata kunci, SEO Title, Slug/Permalink, Meta Description, Image Optimization dan konten, menambahkan Deskripsi text dan title gambar dan melakukan Backlink ke halaman website disetiap sosial media dan blog yang dimiliki seperti Facebook Page, Instagram dan Blogger. Kemudian Submit Website ke google Search Console (GSC) dengan cara klik inspeksi pada halaman GSC dan masukkan URL setiap kali terdapat perubahan pada setiap halaman website dan klik untuk pengindeks-an agar halaman diindex oleh Google. Pada Gambar 12 merupakan contoh hasil pencarian kata kunci.

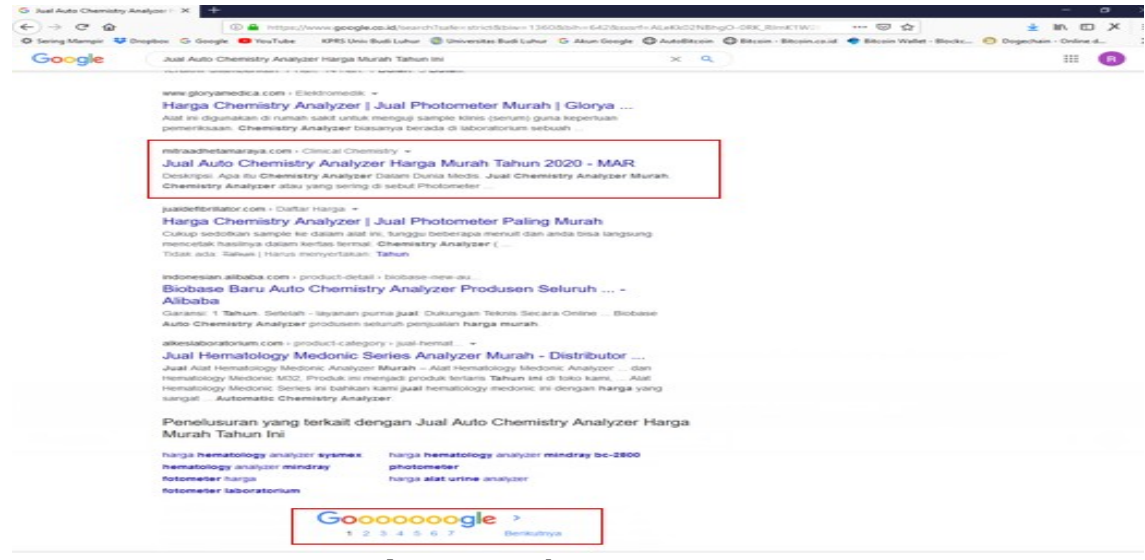

Gambar 12. Hasil Pencarian Kata Kunci

\section{KESIMPULAN}

Berdasarkan penelitian yang sudah dilakukan dari tahapan analisis, dan pembahasan dapat diambil beberapa kesimpulan yaitu: (a) Dengan menggunakan Business Model Canvas sangat membantu Mitra Adhetama Raya dalam mengenali ruang lingkup yang dibangun dan ditunjukan dalam sebuah BMC yang 
INDONESIA JOURNAL INFORMATION SYSTEM (IDEALIS)

Volume 4, Nomor 1, Januari 2021

ISSN 2684-7280 (online)

Halaman 73-82

available online at http://jom.fti.budiluhur.ac.id/index.php/IDEALIS/index

terbentuk saling terkait dari 9 Blok elemen yang ada. (b) Dengan adanya media website penjualan online alatalat kesehatan e-commerce ini dapat membantu Mitra Adhetama Raya dalam meningkatkan hasil penjualan produk Alkes dan membantu aktivitas pengelolaan data menjadi lebih akurat dan efektif. (c) Proses penjualan tidak hanya dapat dilakukan pada area yang lebih luas lagi dan juga mampu memberikan informasi lebih detail, lengkap dan lebih banyak menawarkan promosi kepada pelanggan. (d) Website Mitra Adhetama Raya dapat menampilkan informasi produk-produk alat kesehatan yang ditawarkan. (e) Dengan adanya fitur produk terlaris, calon pembeli dapat mengetahui produk yang paling diminati pada Mitra Adhetama Raya sehingga pembeli tidak membandingkan dengan produk di website lainnya. (f) Website e-commerce Mitra Adhetama Raya sudah teroptimasi dengan teknik SEO On-Page yang telah dilakukan agar website berada pada halaman pertama pada mesin pencari Google. (g) Promosi dilakukan pada social media Instagram yang akan backlink ke website utama e-commerce yang sudah teroptimasi.

\section{DAFTAR PUSTAKA}

[1] N. Iriadi and F. Dayanti, “Sistem Informasi Penjualan Produk Fashion Hijab Berbasis Web Pada Toko Refida”, Indonesian Journal of Network Security, vol. 9, no. 5, pp. 36-40, 2020.

[2] A. Wirapraja and H. Aribowo, "Pemanfaatan E-Commerce Sebagai Solusi Inovasi Dalam Menjaga Sustainability Bisnis”, Teknika, vol. 7, no. 1, pp. 66-72, 2018.

[3] G. A. P. Noor and S. Samsinar, "Implementasi E-Commerce Menggunakan Content Management System Untuk Pemasaran Produk Pada Lumi Distro Dengan Pendekatan Business Model Canvas,” IDEALIS, vol. 3, no. 1, pp. 552-559, 2020.

[4] S. Kosasi and I. D. A. E. Yuliani, "Penerapan Rapid Application Development Pada Sistem Penjulalan Sepeda Online", Jurnal Simetris, vol. 6, no. 1, pp. 27-36, 2017.

[5] S. M. Maulana, H. Susilo, and Riyadi, "Implementasi E-commerce Sebagai Media Penjualan Online (Studi Kasus Pada Toko Pastbrik Kota Malang)”, Jurnal Administrsi Bisnis, vol. 29, no. 1, pp. 1-9, 2015.

[6] H. Sutri, “Perancangan Sistem Informasi Penjualan Berbasis E-Commerce Studi Kasus Toko Kun Jakarta,” Ilkom Jurnal Ilmiah, vol. 10.2, pp. 182-189, 2018.

[7] L. P. Boedianto, “Strategi Pengembangan Bisnis Pada Depot Selaris Dengan Pendekatan Business Model Canvas”, Agora, vol. 3.2, pp. 292-301, 2015.

[8] A. Jackson, “Evaluasi dan Perancangan Model Bisnis Pada Kaisar Organizer Dengan Business Model Canvas”, Agora, vol. 3.2, pp. 302-305, 2015.

[9] A. Hendini, "Pemodelan UML Sistem Informasi Monitoring Penjualan dan Stok Barang (Sudi Kasus: Distro Zhezha Pontianak)," Junal Khatulistiwa Informatika, vol. IV, no. 2, pp. 107-116, 2016.

[10] A. Pratomo, E. Najwaini, A. Irawan, and M. Risa, "Optimasi e-Commerce dengan Penerapan Teknik SEO (Search Engine Optimization) Untuk Meningkatkan Penjualan Pada UKM Nida Sasirangan,” Jurnal Impact Implementation and Action, vol. 1, no. 1, pp. 35-47, 2018. 